\title{
Hemispheric asymmetries for the conscious and unconscious perception of emotional words
}

\author{
Stephen D. Smith and M. Barbara Bulman-Fleming \\ Department of Psychology, University of Waterloo, Ontario, Canada
}

\begin{abstract}
The current research examines the interactions between hemispheric asymmetries for visual perception and emotion. In a series of four experiments, participants completed tasks measuring both conscious and unconscious perception of linguistic stimuli. In these studies, stimulus-presentation parameters (brief exposure duration vs masking) and the emotional valence of the test stimuli (negative vs positive) were manipulated in order to create studies in which the visual and emotional asymmetries were congruent (favoured the same hemispheres) or were incongruent (favoured opposing hemispheres). The results demonstrated that negative emotional stimuli led to a right-hemisphere advantage for conscious perception only when stimuli were shown for brief exposures $(17 \mathrm{~ms})$. Positive emotional words did not elicit hemispheric asymmetries. The results are discussed in terms of their relevance for theories of emotional lateralisation.
\end{abstract}

How do the two cerebral hemispheres differ in their ability to perceive emotional information, and what factors influence these asymmetries? Previous research has demonstrated that the right hemisphere $(\mathrm{RH})$ is faster and more accurate than the left hemisphere $(\mathrm{LH})$ at encoding negative emotional stimuli (e.g., fear or anger; see Davidson, 1995, for a review). In contrast, the encoding of positive emotional stimuli (e.g., happiness) does not appear to elicit a consistent pattern of hemispheric asymmetries. This inconsistency has led to the development of two separate theories of the laterality of emotional perception. The right-hemisphere hypothesis suggests

Address correspondence to: Stephen D. Smith, Department of Psychology, Vanderbilt University, 301 Wilson Hall, 111 21st Avenue, Nashville, Tennessee 37203, USA. Email: stephen.d.smith@vanderbilt.edu

The research reported in this paper was supported by a Natural Sciences and Engineering Research Council (NSERC) of Canada grant to M.B.B-F., as well as an NSERC post-graduate scholarship and Ontario Graduate Scholarships to S.D.S. This paper benefited from the comments of Al Cheyne, Mike Dixon, Jim Frank, Gina Grimshaw, Mike Peters, and two anonymous reviewers. We are grateful for the research assistance of Shannon Waterfield, Crissa Guglietti, Rajwant Sandu, Sarah Lemay, Corey Birch, Nadine Laudi, Andreas Richter, Norman Farb, Melissa McFadden, and Jennifer Lepock.

(C) 2006 Psychology Press Ltd

http://www.psypress.com/laterality

DOI: $10.1080 / 13576500600572404$ 
that all emotion, regardless of valence (positive or negative), is preferentially processed by the RH (e.g., Borod, Cicero, Obler, Welkowitz, Erhan, Santschi, et al., 1998; Cicero et al., 1999). In contrast, the valence hypothesis posits that negative information is processed more efficiently by the RH but that positive information is processed more efficiently by the LH (e.g., Canli, Desmond, Zhao, Glover, \& Gabrieli, 1998; Canli et al., 1999; Davidson \& Irwin, 1999). As both theories are supported by substantial previous research, it is clear that factors other than emotional processing influence the resulting patterns of laterality. For instance, gender (Canli, Desmond, Zhou, \& Gabrieli, 2002) and previous episodes of depression (Atchley, Ilardi, \& Enloe, 2003) have been shown to influence patterns of hemispheric asymmetries. In the studies reported in this paper, we investigated the influences of two variables: awareness and presentation characteristics. Specifically, we investigated the effects of manipulating exposure duration and stimulus masking on hemispheric asymmetries for the conscious and unconscious perception of emotional information.

Presentation parameters such as exposure duration or masking can greatly influence hemispheric asymmetries for visual perception. For example, there is an RH advantage for the perception of information presented for very brief exposure durations (Sergent, 1982, 1983). Rizzolatti and Buchtel (1977) presented stimuli to individual visual fields and noted that the RH advantage occurred until the exposure duration was increased to $150 \mathrm{~ms}$. In contrast, presenting two stimuli close together in time, such as occurs in a typical masking experiment, conferred a processing advantage to the LH (Nicholls, 1994, 1996). For example, Oscar-Berman and colleagues (Oscar-Berman, Goodglass, \& Cherlow, 1973) found that the LH was able to process masked stimuli at shorter stimulus onset asynchronies (SOAs) than the RH. Indeed, previous work in our laboratory has confirmed these findings: Emotionally neutral words presented briefly $(17 \mathrm{~ms})$ to one hemisphere or the other resulted in superior processing by the $\mathrm{RH}$, whereas words presented for a longer duration followed by a mask revealed an LH advantage (Smith \& Bulman-Fleming, 2001). In order to ascertain whether hemispheric differences for emotional perception are influenced by asymmetries for visual characteristics, it is necessary to present emotional and neutral stimuli using two different sets of presentation parameters, one favouring each hemisphere.

In earlier work (Smith \& Bulman-Fleming, 2004), we reported a study involving neutral and negative words laterally presented under conditions favouring the $\mathrm{RH}$. The logic to this approach was to create a situation in which both the visuoperceptual asymmetry (brief exposure duration) and emotional asymmetry (negative emotion) favoured the same hemisphere (right). We demonstrated hemispheric asymmetries for the conscious and unconscious perception of negatively valenced words. Specifically, negative 
words presented to the $\mathrm{RH}$ led to greater levels of conscious perception than negative words presented to the LH or neutral words presented to either hemisphere. Critically, negative words presented to the RH led to reduced levels of unconscious perception, suggesting that the RH superiority for conscious perception occurred at the expense of unconscious perception.

In the current research we have replicated and extended our previous findings (Smith \& Bulman-Fleming, 2004) by examining the interaction between visuoperceptual and emotional asymmetries. Specifically, we report four experiments in which the factors Word Emotion (positive; negative) and Presentation Type (unmasked; masked) were completely crossed. Experiment 1a was a replication of Smith and Bulman-Fleming (2004) described above, in which negative emotional words were presented for $17 \mathrm{~ms}$ unmasked. Experiment 1b, which involved negative stimuli presented for 136 ms followed by a mask, tested whether we would find hemispheric differences if presentation characteristics were not concordant with the emotional valence of the words (i.e., if the two factors favoured opposite hemispheres). Experiments $2 \mathrm{a}$ and $2 \mathrm{~b}$ tested the relative generalisability of the right-hemisphere and valence hypotheses. In Experiment 2a, positive and neutral words were presented for $17 \mathrm{~ms}$ without a mask. If the righthemisphere hypothesis is correct, and positive emotional words are processed by the $\mathrm{RH}$, then the visuospatial and emotional asymmetries would both favour the $\mathrm{RH}$. We would therefore expect a pattern of results very similar to that found in Smith and Bulman-Fleming (2004) or our replication of this study-Experiment 1a. In Experiment 2b, positive and neutral words were presented for the longer exposure duration and were masked. If the valence hypothesis is correct, and positive emotional words are processed by the $\mathrm{LH}$, then the visuospatial and emotional asymmetries would both favour the LH. If this is the case, then we would expect to find an LH processing advantage. To summarise, if the right-hemisphere hypothesis is supported, hemispheric asymmetries for the perception of emotion should be found in Experiments 1a and 2a; if the valence hypothesis is supported, these asymmetries should be found in Experiments $1 \mathrm{a}$ and $2 \mathrm{~b}$.

\section{EXPERIMENT 1A: NEGATIVE VS NEUTRAL WORDS (17 MS)}

\section{Method}

Participants. A total of 64 undergraduate students (40 females and 24 males) from the University of Waterloo participated in this experiment in exchange for bonus credit in an Introductory Psychology course or for monetary remuneration. All of the participants who took part in the experiments reported in this paper signed a consent form before taking part in an experiment, as required by the Office of Research Ethics, University of 
Waterloo. All participants had normal or corrected-to-normal vision and were right-handed. English was the first language of all participants.

Stimuli and apparatus. The stimuli used in Experiment 1a consisted of two separate lists of 120 words ranging in length from five to seven letters. One set consisted of target words and one set consisted of baseline words. Both sets of words included 60 negative and 60 neutral items. The classification of the word as emotional or neutral was verified with pretesting during which a separate group of participants $(N=24 ; 8$ males and 16 females) were asked to rate each of 300 words as being positive, negative, or neutral. Only words that were unanimously judged to be negative were included as stimuli in Experiments 1a and 1b. Of these 120 negative words, 60 served as target words and 60 served as baseline words. (Please see Appendices for all stimuli used in all the experiments reported here.)

For each target word, the word length, word frequency (norms from Kuçera \& Francis, 1967), emotion type (negative or neutral), and number of possible word-stem completions were calculated. Each target word was then matched with a baseline word that was equivalent on each of these four variables. On each trial, the selected target or baseline word was presented for $17 \mathrm{~ms}$ to the left visual field or the right visual field. The side of presentation was randomised with the constraint that each participant would receive 15 Negative-Target, 15 Neutral-Target, 15 Negative-Baseline, and 15 Neutral-Baseline words presented to each hemisphere (120 total trials). Each word was presented vertically such that the middle of the word was presented at the vertical centre of the screen. Words were presented vertically in order to ensure that the end of the word-critical for stem completion - was an equal distance from fixation for both $\mathrm{LH}$ and $\mathrm{RH}$ trials (Bryden, Mondor, Loken, Ingleton, \& Bergstrom, 1990). On target trials, the three-letter word stem was derived from the presented word; in contrast, on baseline trials, the word stem did not match the presented baseline word but rather was the word stem derived from the companion target word (which was not presented). On average, words measured $4 \mathrm{~mm}$ in width and $32 \mathrm{~mm}$ in height. The distance from the central fixation cross to the middle of the word was $30 \mathrm{~mm}$.

All materials were presented on a 17 -inch ViewSonic monitor that was connected to a $450 \mathrm{MHz}$ Pentium 3 processor. The contrast of the monitor was digitally set to $75 \%$ and the brightness was digitally set to $25 \%$. Stimuli were presented using E-Prime software (Psychology Software Tools, 2001) and were white against a black background.

Participants also completed three paper-and-pencil questionnaires. The Positive and Negative Affect Scale (Watson, Clark, \& Tellegen, 1988) is a 20item mood-assessment questionnaire consisting of a series of positive and negative adjectives (e.g., distressed, interested). Participants indicate, using a 
scale ranging from 1 (very little or not at all) to 5 (extremely), how much each adjective applies to their current mood. The Beck Depression Inventory II (Beck \& Steer, 1993) is a 21-item questionnaire that assesses whether participants are depressed; each multiple-choice question has four responses, ranging in value from 0 to 3 points. A higher score indicates a greater degree of depression. The Waterloo Handedness Questionnaire (Elias, Bryden, \& Bulman-Fleming, 1998) is a 37-item questionnaire in which participants indicate which hand (left or right) they prefer to use for a given task (e.g., brushing one's teeth). Participants can circle "Left always", "Left usually", "Equal", "Right Usually", or "Right Always" for each item. Each item is then scored (from -2 for "Left always" to +2 for "Right always), and a degree-of-handedness score is then calculated.

Experimental tasks. Conscious and unconscious perception were measured by having participants make two separate responses on each trial (see Figure 1). The degree of conscious perception was assessed by having participants make a report of subjective awareness on each trial. After a word had been presented, the participants were asked to indicate if they had seen the entire word, part of the word, or nothing at all. The degree of unconscious perception was measured using a word-stem completion test called the exclusion task (Debner \& Jacoby, 1994; Jacoby, 1991; Merikle, Joordens, \& Stolz, 1995). In this task, participants are asked to complete three-letter word stems to make a legitimate English word. Critically, they are told to complete the word stem with the first word that comes to mind other than the presented word. If participants consciously perceived the word, then they will follow the task instructions and use a different word to complete the word stem. In contrast, if participants unconsciously perceived the word, then this primed word will be the most available word to the participant; the result will be that participants use the word to complete the word stem. The beauty of the exclusion task is that it allows researchers to separate conscious and unconscious perception rather easily; the two types of perception lead to qualitatively different patterns of results (Debner \& Jacoby, 1994; Merikle \& Joordens, 1997; Merikle et al., 1995). These two measures, subjective reports and the exclusion task, were used in the current studies to quantify the degree of conscious and unconscious perception, respectively.

Procedure. Participants completed the Positive and Negative Affect Scales (Watson et al., 1988), and the Waterloo Handedness Questionnaire (Elias et al., 1998). After filling out these questionnaires, participants completed two computer tasks.

The first computer task consisted of the word-stem completion task described above. Each trial began with a 500-ms presentation of a fixation 
Target Trial Baseline Trial

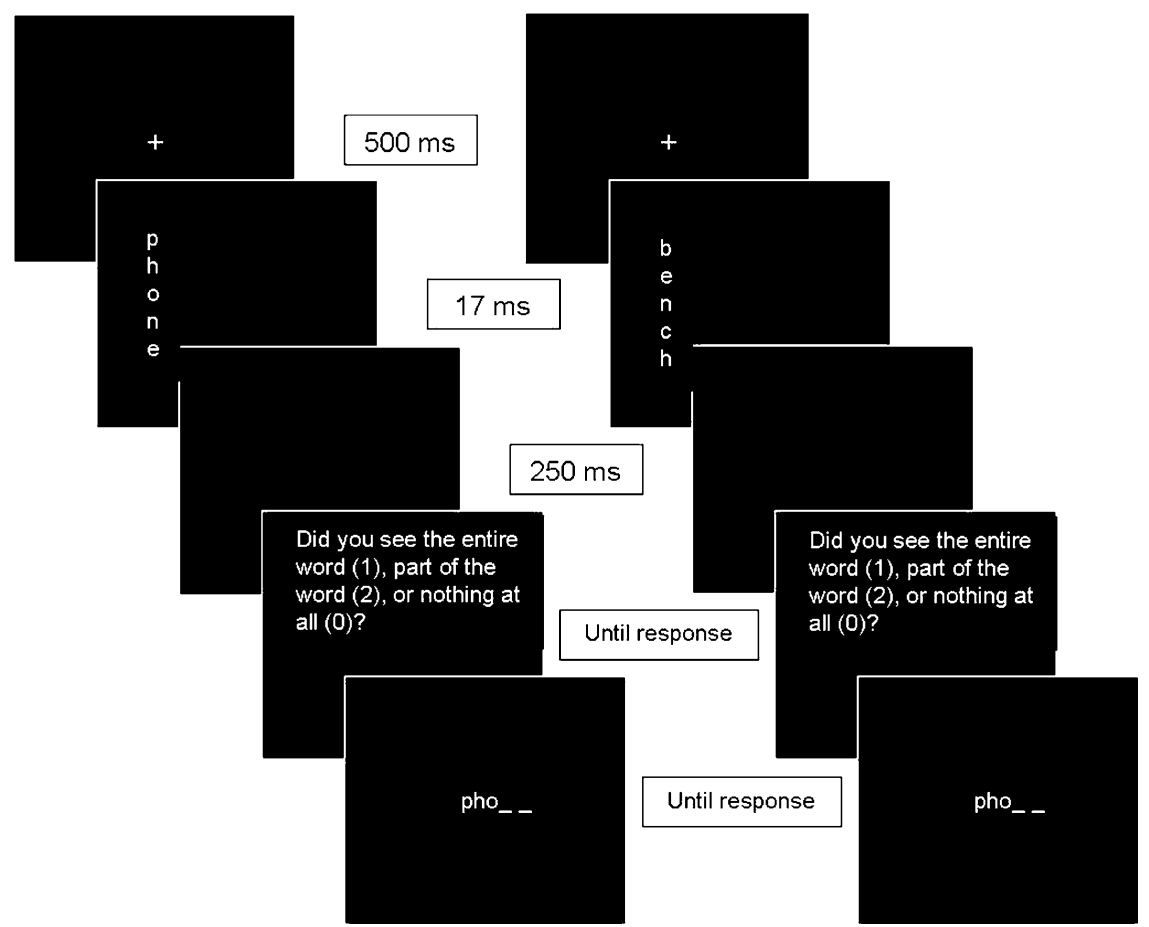

Figure 1. The sequence of events for target and baseline trials in Experiments 1a and 2a. In Experiments $1 \mathrm{~b}$ and $2 \mathrm{~b}$, the $250 \mathrm{~ms}$ blank screen following the vertical presentation of the word was replaced by a 136-ms presentation of a mask consisting of a vertical string of ampersands (\&\&\&\&\&\&\&). All other procedures were identical across the experiments.

cross ("+") displayed at the horizontal and vertical centre of the screen. After $500 \mathrm{~ms}$, the cross disappeared and was replaced by a vertically presented word that was displayed for $17 \mathrm{~ms}$. After a 250-ms blank screen (to avoid masking the stimulus with the sudden onset of another stimulus), the question "How much of the word were you able to see?" appeared on the screen. This question was accompanied by three options. Participants were asked if they had seen the entire word, part of the word, or nothing at all, and responded by pressing a number on the keyboard that corresponded to each option. Each trial ended with the presentation of a word stem that consisted of three letters and either two, three, or four blank spaces corresponding to whether the presented word was five, six, or seven letters in length, respectively. The participants were instructed to type in the missing letters in order to complete the word stem with the first word that came to mind other than the word presented on that trial. Each word stem remained 
on the screen until the participants entered enough letters to fill the blank spaces and make an English word. After the computer accepted the completion of the word stem, the participants pressed the spacebar to initiate the next trial.

The second computer task required participants to rate the emotional valence (neutral or negative) of a series of words on a scale ranging from very positive to very negative. The stimuli for this word-rating task consisted of the 120 target (60 negative and 60 neutral) and 120 baseline (60 negative and 60 neutral) words used in the exclusion task. The purpose of this task was to ensure that participants viewed the negative words as being emotionally negative and viewed the neutral words as being emotionally neutral. Each trial began with a central fixation cross displayed for $500 \mathrm{~ms}$. Following the disappearance of the fixation cross, a word was presented centrally for $1000 \mathrm{~ms}$. After this presentation, a dialogue box appeared on the screen containing a list of options: very negative, negative, somewhat negative, slightly negative, slightly positive, somewhat positive, positive, and very positive. Participants were asked to indicate which option corresponded to the word displayed on that trial. All 120 baseline and 120 target trials were presented in a randomised order to each participant.

Participants completed the Beck Depression Inventory II (Beck \& Steer, 1993 ) at the end of the experimental session. Any participant with a BDI-II score of 13 or above was removed from the analyses in order to reduce the influence of depression on our investigation of hemispheric asymmetries (see Bruder, 1995, for a review of these effects).

Analyses. On each trial, participants were asked to indicate if they had perceived the entire word, part of the word, or nothing at all. These data are referred to as "subjective-report data". Trials on which the participant perceived the entire word are hereafter referred to as "conscious trials". "Unconscious trials" consist of trials on which the participants claimed to have seen part of the word and trials on which participants claimed to have seen nothing. These two responses were combined into the larger category of "unconscious perception" because previous research (Smith \& Merikle, 2000,2005 ) has shown that claiming to see part of an item and claiming to see nothing at all lead to the same pattern of results on tests of unconscious perception. Therefore, combining the data from these two responses simplifies the explanation of the results without compromising the rigour of the statistical analyses.

For the analyses of the subjective-report data, the number of conscious trials was tabulated for each participant. Because an increase in the number of trials reported as being consciously perceived necessarily led to a decrease in the number of trials reported as being unconsciously perceived, analyses were conducted only for the number of conscious trials. Thus, the data from 
the subjective report analyses reflect the average number of trials that were consciously perceived by the participants.

Separate analyses were conducted on the data from the exclusion task. Participants' responses on the subjective-report measure were used to divide the exclusion-task data into two separate categories: "consciously" and "unconsciously" perceived words. The dependent variable in the exclusion task was the proportion of times the target word was used to complete the word stem (exclusion failures). The proportion of exclusion failures for target words (e.g., phone followed by pho-) was compared to that for baseline words (e.g., chair followed by pho-). If the levels of exclusion failures were below baseline levels, it was assumed that conscious perception had occurred because participants did not use the primed word to complete the word stem. In contrast, if the levels of exclusion failures were above baseline levels, it was assumed that unconscious perception had occurred; a primed word that was unconsciously perceived would be the most available completion to the word stem. In the current studies, the proportion of exclusion failures was calculated for each participant for each condition (consciously and unconsciously perceived emotional and neutral words presented to the $\mathrm{LH}$ and $\mathrm{RH}$ ), resulting in eight data points per participant.

In sum, the two key dependent variables in the studies reported in this paper are (1) the number of trials labelled "conscious" in the subjectivereport task and (2) the proportion of exclusion failures. These variables provide information about levels of conscious and unconscious perception, respectively. Each task was analysed in an omnibus repeated-measures analysis of variance, with planned contrasts for emotional versus neutral stimuli within the same hemisphere, as well as between-hemisphere comparisons (e.g., negative stimuli presented to the $\mathrm{RH}$ vs negative stimuli presented to the $\mathrm{LH}$ ).

\section{Results and discussion}

The data from the subjective-report task were analysed in a 2 (Hemisphere) $\times 2$ (Emotion) repeated-measures ANOVA. The results replicated those of our earlier work (Smith \& Bulman-Fleming, 2004). The Emotion $\times$ Hemisphere interaction was significant: $F(1,63)=8.54, M S E=13.53$, $p<.01$. As can be seen in Figure 2a, this interaction is due to the $\mathrm{RH}$ superiority for the perception of negative emotional information. There were many more conscious trials for negative than for neutral trials for $\mathrm{RH}$ presentations; there was no effect of emotion for trials presented to the LH. This RH preference for negative information also led to a main effect of Emotion: $F(1,63)=4.61, M S E=7.25, p<.05$. Negative words were more likely to be consciously perceived than were neutral words. As well, 

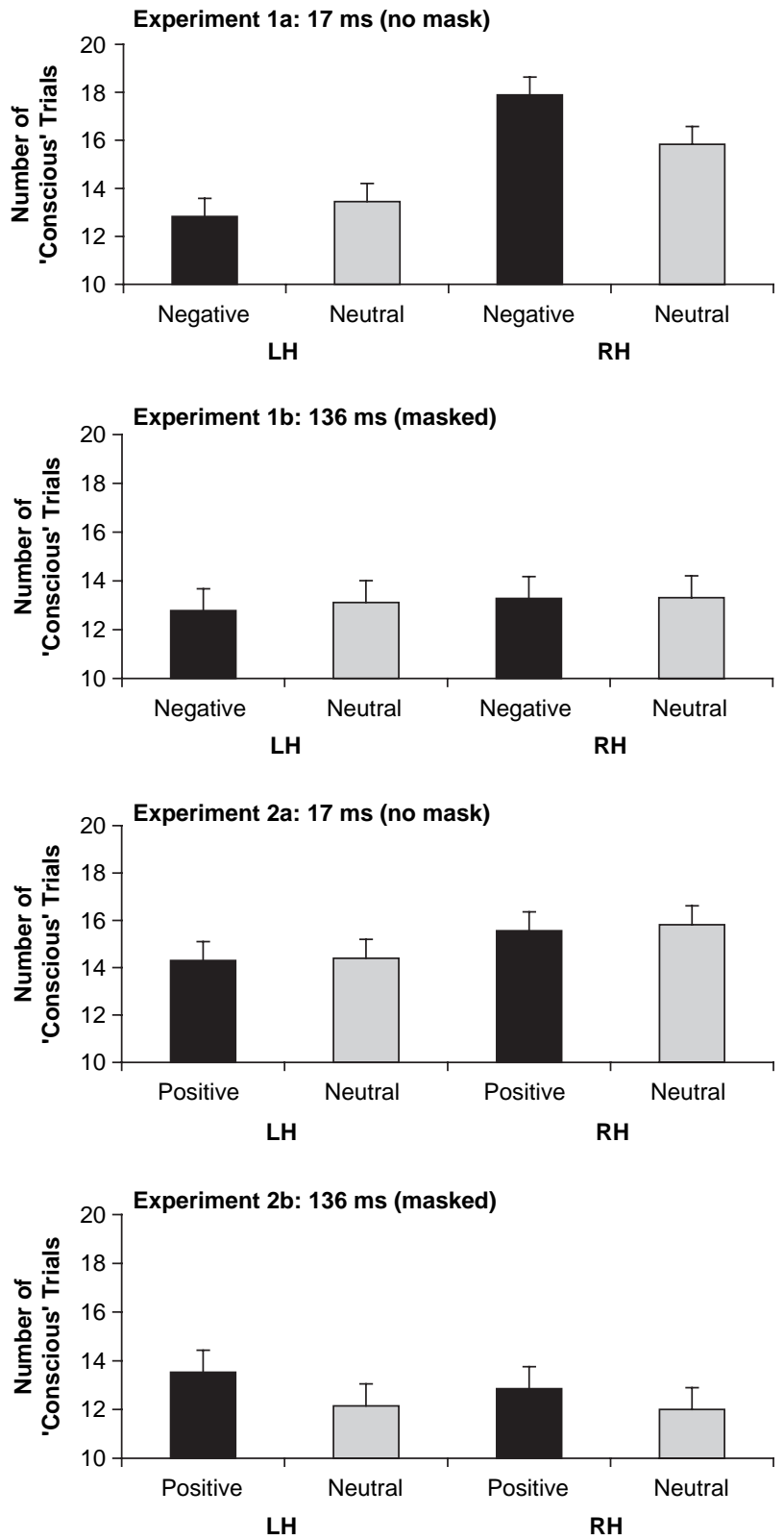

Figure 2. The number of trials labelled as being "conscious" for each stimulus type across hemispheres. The titles of Figure $2 \mathrm{a}-\mathrm{d}$ indicate the experiment being depicted. Error bars represent standard error of the mean. 

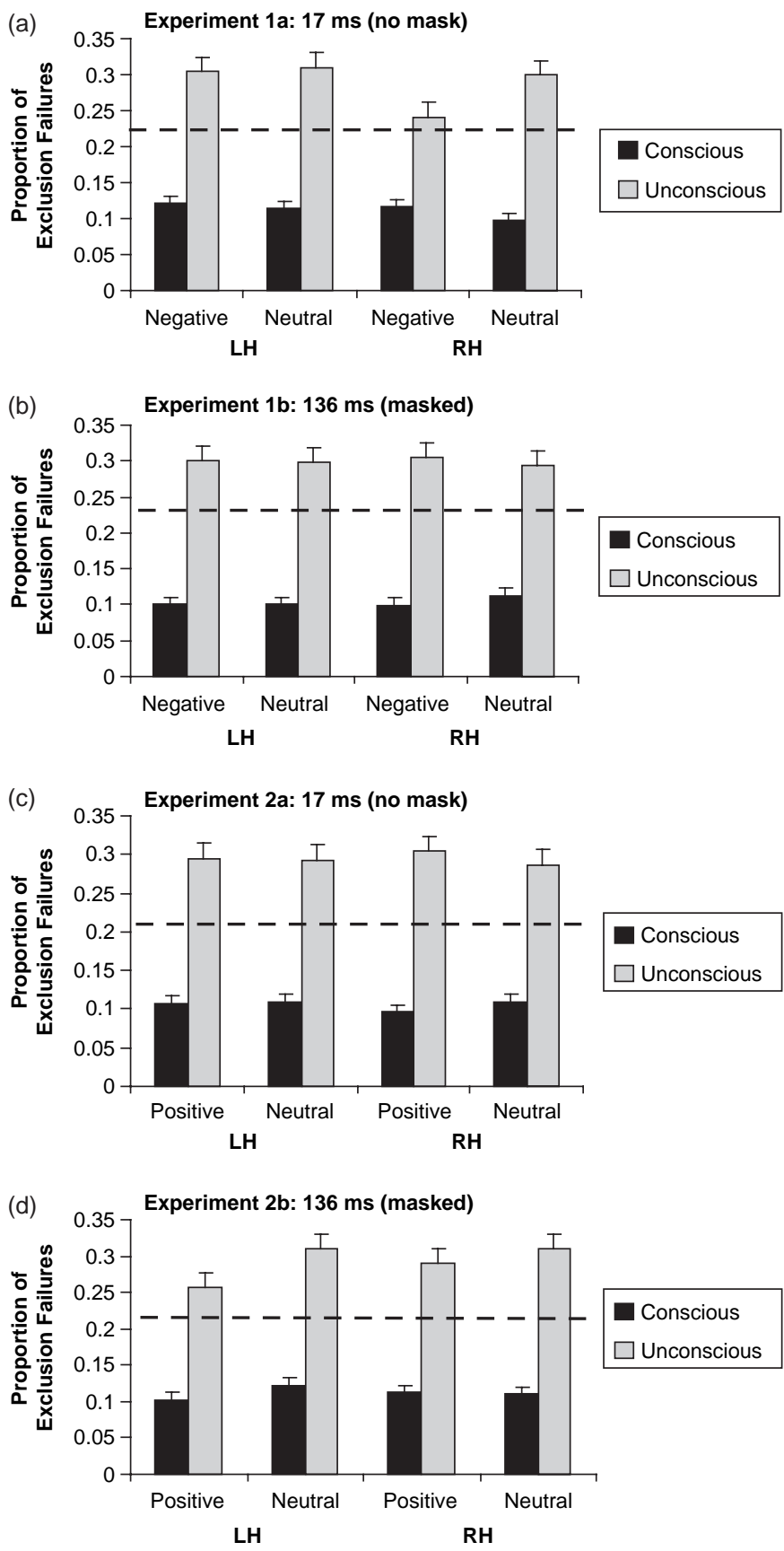

Figure 3 (see overleaf for caption) 
Experiment 1a resulted in the predicted overall $\mathrm{RH}$ advantage for visual perception: $F(1,63)=35.04, M S E=25.31, p<.0005$.

Planned contrasts performed on the subjective-report data also replicated our earlier work. A matched-pairs $t$-test demonstrated that on $\mathrm{RH}$ trials, the average number of "conscious" trials was greater for negative $(M=17.89$, $S E M=0.79)$ than for neutral $(M=15.83, S E M=0.61)$ words: $t(63)=4.15, p<.005$. In contrast, on LH trials, there was no difference between the number of "conscious" trials for negative $(M=12.83$, $S E M=0.75)$ and neutral $(M=13.45, S E M=0.84)$ words: $t<1$. Finally, the number of conscious trials for negative words presented to the RH was significantly greater than that for negative words presented to the LH: $t(63)=6.53, p<.001$. This pattern of results replicates our earlier work and demonstrates that the $\mathrm{RH}$ is superior to the $\mathrm{LH}$ at the conscious perception of negative emotional information, at least at short exposure durations.

The data from the exclusion task were analysed in a 2 (Awareness) $\times 2$ (Hemisphere) $\times 2$ (Emotion) repeated-measures ANOVA. The threeway interaction between these variables was statistically significant: $F(1,63)=3.96, M S E=0.0072, p<.05$. As can be seen in Figure 3a, for unconscious trials, the RH showed less unconscious perception for negative than for neutral trials, which was not the case for $\mathrm{LH}$ unconscious trials. There were no hemispheric differences on the exclusion task when the words were consciously perceived. Thus, the three-way interaction is being driven by the right-hemisphere inferiority for unconsciously perceiving negative information. This effect also led to a significant Emotion $\times$ Hemisphere interaction: $F(1,63)=4.75, M S E=0.0060, p<.04$. Negative emotion was unconsciously perceived less well by the RH than by the $\mathrm{LH}$; the perception of neutral words did not differ between the hemispheres. There was also a significant Awareness $\times$ Emotion interaction: $F(1,63)=$ 4.88, $M S E=0.0068, p<.04$. Pooling hemispheres, there was less unconscious perception (i.e., a lower level of exclusion failures; light bars on Figure 3a) for negative than for neutral trials; however, there was no Emotion difference on this measure for trials labelled "conscious", on which participants saw the entire word (dark bars on Figure 3a).

Figure 3 (previous page). The mean proportion of exclusion failures for "conscious" and "unconscious" trials. The titles of Figure $3 \mathrm{a}-\mathrm{d}$ indicate the experiment depicted. In all figures, the dashed line represents the mean baseline level of exclusion failures. Error bars indicate the standard error of the mean. Note that in Figure 3a the proportion of exclusion failures for negative words presented to the right hemisphere did not differ from that for baseline levels; this bar is significantly different from the other three "unconscious" categories. In Figure $3 \mathrm{~d}$ the proportion of exclusion failures for positive words presented to the left hemisphere was considerably reduced compared to the other trial types; this difference was marginally significant. 
Matched-pairs $t$-tests were performed in order to compare the proportion of exclusion failures for target and baseline trials for those trials labelled conscious. These contrasts were conducted for negative words presented to the right hemisphere, negative words presented to the left hemisphere, neutral words presented to the right hemisphere, and neutral words presented to the left hemisphere. The proportions of exclusion failures were significantly below baseline for negative and neutral words presented to either hemisphere (all four $t$-values were $>4.80$ ), so the participants clearly understood the instructions for the exclusion task. Additionally, in three out of the four "unconscious" conditions, the proportions of exclusion failures were significantly above baseline levels. This pattern of data implies that, in these three conditions, the participants unconsciously perceived the word, so they failed to exclude it when completing the word stem. Unconscious perception occurred for neutral words presented to the $\mathrm{RH}, t(63)=3.72$, $p<.005 ; M=0.296, S E M=0.014$, neutral words presented to the LH, $t(63)=3.85, p<.005 ; M=0.297, S E M=0.014$, and negative words presented to the LH, $t(63)=2.85, p<.01 ; M=0.304, S E M=0.014$. These results demonstrate that the methodology used was sensitive enough to detect unconscious perception. Finally, the proportion of exclusion failures for unconsciously perceived negative words presented to the RH (the condition that led to the greatest amount of "conscious" perception in the subjective-report task) did not differ from baseline levels: $t(63)=1.14$, $p=.26$. Critically, this data point $(M=0.243, S E M=0.012)$ was significantly different from the other three "unconscious" perception data points depicted in Figure 3a (all $t$-values $>2.60$ ).

Post-hoc analyses were conducted to determine if male and female participants differed on their performance on the subjective-report or exclusion tasks. We found no evidence for gender differences on either task; in addition, no gender effects were found in any of the studies reported in this paper. Therefore, the variable of participant gender will not be discussed further.

In Experiment 1a, the number of trials labelled "conscious" by the participants was greatest for negative words presented to the RH. This advantage for conscious perception appears to have occurred at the expense of unconscious perception, because there is no evidence of unconscious perception for negative words presented to the RH. These data suggest that for words briefly presented with no mask, the threshold for conscious perception of negative words in the right hemisphere is lower than it is for neutral words in that hemisphere or for neutral or negative words in the left hemisphere. 


\section{EXPERIMENT 1B: NEGATIVE VS NEUTRAL WORDS (MASKED)}

Experiment $1 \mathrm{~b}$ allowed us to determine if the $\mathrm{RH}$ advantage for processing negative emotional words would interact with the $\mathrm{LH}$ advantage for the visual perception of items presented in close temporal proximity (i.e., the perception of masked words). In this experiment, the presentation parameters favoured the LH (Oscar-Berman et al., 1973). Depending on the relative strengths of the hemispheric asymmetries, one might predict an $\mathrm{RH}$ effect (if the emotional effect prevailed), an LH effect (if the visuoperceptual characteristics were more robust), or that the two effects would cancel each other out.

\section{Method}

Participants. A total of 68 undergraduate participants (22 males and 46 females) completed this experiment in exchange for monetary remuneration or bonus credit in an Introductory Psychology course. All participants were right-handed and had normal or corrected-to-normal vision. Four female participants had a Beck Depression Inventory II score that was greater than 13; their data were removed from the analyses and four additional female participants were tested (final $N=64$ ).

Stimuli and apparatus. The stimuli and apparatus used in Experiment $1 \mathrm{~b}$ were identical to those used in Experiment 1a.

Procedure. The procedure for Experiment $1 \mathrm{~b}$ was identical to that for Experiment 1a with two exceptions. The exposure duration of the stimuli was increased from $17 \mathrm{~ms}$ to $136 \mathrm{~ms}$ and, following the presentation of the word, a pattern mask consisting of seven ampersands was presented vertically for $500 \mathrm{~ms}$. This mask measured $4 \mathrm{~mm}$ in width and $35 \mathrm{~mm}$ in height. The mask was displayed in a vertical line on the same side of the computer as the presented word, with the fourth ampersand in the mask appearing at the vertical centre of the screen. No other changes were made to the procedure.

\section{Results and discussion}

The subjective-report data from Experiment $1 \mathrm{~b}$ are shown in Figure $2 \mathrm{~b}$. These data were analysed in a 2 (Hemisphere) $\times 2$ (Emotion) repeatedmeasures ANOVA. The Emotion $\times$ Hemisphere interaction in this set of analyses was not significant: $F<1$. The main effects of Emotion and Hemisphere also failed to reach significance (both $F$-values $<1$ ). These 
results suggest that there were no differences between the numbers of conscious trials for negative or neutral words presented to either hemisphere. Subsequent planned comparisons confirmed that all four trial types were statistically equivalent (all $t$-values $<1$ ). These findings suggest that the hemispheric asymmetries for emotion and visual perception may influence each other. When neutral words are masked, an LH advantage is found (e.g., Smith \& Bulman-Fleming, 2001); when emotional words are presented for brief exposure durations, an RH advantage is found. But combining these paradigms so that the emotional $(\mathrm{RH})$ and visual $(\mathrm{LH})$ advantages are in opposition seems to cancel out, or eliminate, both RH and LH advantages.

The exclusion-task data also failed to produce any hemispheric differences (see Figure 3b). In this study, all trial types in this study led to significant levels of unconscious perception. This finding stands in contrast to Experiment 1a, in which there was no evidence of unconscious perception for negative words presented to the RH.

Thus, the results of Experiment $1 \mathrm{~b}$ failed to show evidence of a hemispheric asymmetry for the perception of emotion when the asymmetries for emotion and for vision did not favour the same hemisphere.

\section{EXPERIMENT 2A: POSITIVE VS NEUTRAL WORDS (17 MS)}

Proponents of the two theories of emotional lateralisation would disagree as to the predicted results of Experiment 2a. If the right-hemisphere hypothesis is correct, then the results should be very similar to those of Experiment 1a because in Experiment 2a, both the emotional asymmetry (positive words) and the visual asymmetry (short exposure duration) favoured the RH. In contrast, if the valence hypothesis is correct, then the two opposing asymmetries would cancel out any behavioural evidence of hemispheric differences because here the emotional asymmetry favoured the LH and the visual asymmetry favoured the RH.

\section{Method}

Participants. A total of 66 undergraduate participants (33 males and 33 females) completed this experiment in exchange for monetary remuneration or bonus credit in an Introductory Psychology course. All participants were right-handed and had normal or corrected-to-normal vision. Two female participants had a Beck Depression Inventory II score that was greater than 13; the data from these two participants were removed from the analyses and two additional participants were tested (final $N=64$ ).

Stimuli and procedure. The stimuli used in Experiment 2a consisted of two separate lists of 120 words ranging in length from five to seven letters. 
Both sets of words included 60 positive and 60 neutral items. The classification of the word as emotional or neutral was verified during the pre-testing phase discussed in the Method section of Experiment 1a. The positive words used in Experiment 2a were equated with the negative words used in earlier studies in terms of word frequency, word length, number of possible completions (of a word stem consisting of the first three letters of that word), and amount of arousal elicited by the words. Other details of the presentation of the stimuli, as well as the experimental procedure, were identical to those for Experiment 1a.

\section{Results and discussion}

The subjective-report data were entered into a 2 (Emotion) $\times 2$ (Hemisphere) repeated-measures ANOVA. As can be seen in Figure 2c, the Emotion $\times$ Hemisphere interaction predicted by the right-hemisphere hypothesis did not occur: $F<1$. The effect of Emotion was also not significant: $F<1$. In Experiment 1a there was a significant effect of Hemisphere; however, in Experiment 2a this effect, although suggestive of a trend, was not significant: $F(1,63)=3.74, M S E=30.87, p=.057$.

Specific subsets of the subjective-report data were assessed using planned comparisons. The number of trials labelled "conscious" was not significantly different between neutral and positive words for either hemisphere (both $t$-values $<1$ ). The right-hemisphere hypothesis would lead to the prediction that the number of "conscious" trials for positive words would be larger for the RH than for the LH. This prediction was not supported by the data in Experiment 2a: $t(63)=1.56, p=.12$. In contrast, when neutral words were presented, the $\mathrm{RH}$ was marginally superior to the $\mathrm{LH}$ at perceiving the words: $t(63)=1.91, p=.061$. Thus, the right-hemisphere hypothesis was not supported by the subjective-report data.

The data for the exclusion task were analysed in a 2 (Awareness) $\times 2$ $($ Emotion $) \times 2$ (Hemisphere) repeated-measures ANOVA (see Figure $3 \mathrm{c}$ ). None of the interactions in this study was significant (all $F$-values $<1$ ). The only significant main effect was that of Awareness. The pattern of exclusion failures for trials labelled "conscious" was significantly different from that for trials labelled "unconscious", $F(1,63)=222.58, M S E=$ $0.0204, p<.00001$, demonstrating that the participants understood the instructions for the exclusion task.

Planned comparisons revealed that when the words were unconsciously perceived, the proportions of exclusion failures were above baseline levels for positive and neutral words presented to either hemisphere (all $t$-values $>2.78$ and all $p$-values $<.05)$. Even with a strict Bonferroni correction, all of these $t$-values are statistically significant. There was no 
hemispheric difference for the unconscious perception of positive words: $t<1$. Therefore, although the methodology used was sensitive enough to detect unconscious perception, there was no evidence for a hemispheric difference in the unconscious perception of positive words when these words were presented for $17 \mathrm{~ms}$.

The results of Experiment 2a have important implications for theories of the laterality of emotion. The right-hemisphere hypothesis would have predicted more "conscious" perception for positively valenced words in the $\mathrm{RH}$ than in the $\mathrm{LH}$, but there was no evidence of an emotion-based hemispheric asymmetry. Instead, Experiment 2 a showed evidence of only a trend $(p=.057)$ towards a visual asymmetry. Words presented to the $\mathrm{RH}$ were more likely to be "consciously" perceived than were words presented to the $\mathrm{LH}$, but this difference was independent of the emotionality of the words.

If the right-hemisphere hypothesis were generalisable to all behavioural studies, the results of Experiment 2a should have been similar to those of Experiment 1a. The fact that no emotional asymmetry was found in this study suggests that a different hypothesis is needed to explain the lateralisation of emotion. In Experiment 2b, we tested the valence hypothesis by examining conscious and unconscious perception of positive emotional words that are masked.

\section{EXPERIMENT 2B: POSITIVE VS NEUTRAL WORDS (MASKED)}

In contrast to Experiment 1b, Experiment 2b's predicted hemispheric asymmetries, for the words' emotional valence as well as for the presentation characteristics, were concordant. In this study, positive words were presented for $136 \mathrm{~ms}$ with a mask (a visual asymmetry that favours the LH). As the valence hypothesis predicts that positive words are processed primarily by the $\mathrm{LH}$, we predicted that positive words presented to the LH should lead to greater numbers of conscious trials. We also predicted that this LH superiority for conscious perception would occur at the expense of unconscious perception.

\section{Method}

Participants. A total of 68 undergraduate participants (22 males and 46 females) completed this experiment in exchange for monetary remuneration or bonus credit in an Introductory Psychology course. All participants were right-handed and had normal or corrected-to-normal vision. Four participants (three female and one male) had Beck Depression Inventory II scores that were greater than 13; these data were removed from the analyses and 
four additional participants (three female, one male) were tested (final $N=64)$.

Stimuli and procedure. The word sets and apparatus used in Experiment $2 \mathrm{~b}$ were identical to those used in Experiment 2a. The procedure for Experiment $2 \mathrm{~b}$ was identical to that of Experiment $1 \mathrm{~b}$.

\section{Results and discussion}

The subjective-report data were analysed in a 2 (Emotion) $\times 2$ (Hemisphere) repeated-measures ANOVA and are presented in Figure 2d. We had predicted that there would be a greater degree of "conscious" perception for trials presented to the LH, particularly for the perception of positive words. In contrast to our prediction, the Emotion $\times$ Hemisphere interaction was not significant: $F(1,63)=1.19, M S E=3.67, p=.28$, because positive words were more likely to lead to reports of "conscious" perception on trials presented to either hemisphere. Indeed, there was a main effect of Emotion in this study: $F(1,63)=10.68, M S E=7.54, p<.01$, indicating that participants were better able to encode positive than neutral words, regardless of the hemisphere of presentation. The main effect of Hemisphere was not significant: $F(1,63)=1.69, M S E=6.44, p=.20$.

Matched-pairs $t$-tests revealed that, for the $\mathrm{RH}$, there were more "conscious" trials for positive $(M=12.86, S E M=0.82)$ than for neutral $(M=12.00, S E M=0.99)$ words: $t(63)=2.09, p<.05$. For the LH, there were also more "conscious" trials for positive $(M=13.53, S E M=$ $0.84)$ than for neutral $(M=12.15, S E M=0.88)$ words: $t(63)=3.25$, $p<.05$. These results suggest that both hemispheres preferentially process positive information over neutral information. Finally, the valence hypothesis would predict an LH superiority for the perception of positive information. The valence hypothesis only received marginal support, as the LH had a larger number of conscious trials for the perception of positive words than did the RH (13.53 vs 12.86 for the $\mathrm{LH}$ and $\mathrm{RH}$, respectively) but this difference was not statistically significant: $t(63)=1.69, p<.10$. Thus, the subjective-report data do not support the valence hypothesis, although the trend for an $\mathrm{LH}$ advantage for the conscious perception of positive information is in the predicted direction.

The exclusion-task results are depicted in Figure 3d. These data were analysed in a 2 (Awareness) $\times 2$ (Emotion) $\times 2$ (Hemisphere) repeatedmeasures ANOVA. The only effect that approached significance was a main effect of Emotion. The perception of positive words led to a marginally smaller proportion of exclusion failures than did the perception of neutral words: $F(1,63)=3.52, M S E=0.0182, p=.065$. Finally, as with all of 
the previous studies, the main effect of Awareness was significant, indicating that the participants understood the exclusion-task instructions: $F(1,63)=$ 185.56, $M S E=0.0225, p<.001$.

Planned comparisons consisted of contrasts between target and baseline levels of exclusion failures for positive and neutral words presented to each hemisphere. This difference was quite large for neutral words: $t(63)=4.88$, $p<.001$, and $t(63)=4.03, p<.001$, for the LH $(M=0.311, S E M=$ $0.015)$ and RH $(M=0.309, S E M=0.014)$ respectively. The difference for positive words presented to the RH $(M=0.291, S E M=0.021)$ was also highly significant: $t(63)=3.00, p<.005$; however, the difference between target and baseline levels of exclusion failures for positive words presented to the LH $(M=0.258, S E M=0.023)$ showed a smaller degree of unconscious perception: $t(63)=2.21, p<.04$. Thus, although positive words presented to the LH did produce a significant level of unconscious perception, this effect was smaller than was found for the other three "unconscious" data points.

In addition, $t$-tests were conducted to compare the proportion of exclusion failures for target trials in which positive words were presented to the $\mathrm{LH}$ to that for positive words presented to the $\mathrm{RH}$ and neutral words presented to either hemisphere. These contrasts demonstrated that the unconscious perception of neutral words by each hemisphere did differ from the unconscious perception of positive words by the LH: $t(63)=2.04$, $p<.05$, and $t(63)=2.08, p<.05$ for the $\mathrm{RH}$ and $\mathrm{LH}$, respectively. But there was no hemispheric difference for the unconscious perception of positive information: $t(63)=1.12, p<.27$. These results suggest that there is likely some preference for the perception of positive information by the LH; however, this difference is too small to be detected using the current methodology. Possible solutions to this problem are analysed in the general discussion.

\section{GENERAL DISCUSSION}

The experiments presented in this paper extend previous research by examining how the two cerebral hemispheres process emotional information, both at a conscious and at an unconscious level, and provide important information about the interaction between asymmetries for visual perception and asymmetries for the processing of emotion. In Experiment 1a, negative and neutral words were presented for $17 \mathrm{~ms}$ to either visual field. There was an RH advantage for the "conscious" perception of negative words. These trials were labelled as being consciously perceived more often than was any other type of trial. Critically, this advantage for conscious perception appeared to occur at the expense of unconscious perception, which was not detected for negative words presented to the RH. In Experiment 1b, negative 
and neutral words were shown for $136 \mathrm{~ms}$ before being masked. In this study, the visual and emotional asymmetries presumably favoured different hemispheres. The result of this conflict was that no hemispheric differences were detected, suggesting that the asymmetries may have cancelled each other out. In Experiment 2a, the right-hemisphere hypothesis of emotional lateralisation was tested. Here, positive and neutral words were presented to either hemisphere for $17 \mathrm{~ms}$. Contrary to predictions generated from this theory, there were no hemispheric asymmetries for the perception of positive emotional words. Finally, in Experiment $2 b$, positive and neutral words were presented for $136 \mathrm{~ms}$ before being masked. This experiment tested the veracity of the valence hypothesis, as both the emotional stimuli (positive words) and the visual-input characteristics (masking) favoured the LH. The results of this study were not statistically significant, but the trends were in the predicted directions. There was an LH advantage for the conscious perception of positive words and this advantage occurred at the expense of unconscious perception.

The data from these four experiments were also combined into a larger analysis with Experiment serving as a between-subjects variable. This combined analysis increased statistical power and provided the opportunity to tease apart smaller effects not detected in previous analyses. Although the resulting subjective-report data were interesting, all of the main effects and interactions were driven by the larger $\mathrm{RH}$ advantage for consciously perceiving negative words presented for $17 \mathrm{~ms}$. This trend is likely related to the exclusion-task results. In these analyses, the main effects and interactions were driven by the smaller levels of unconscious perception in the RH during the encoding of negative words presented for $17 \mathrm{~ms}$. In other words, the data from Experiment 1a had a much larger effect on these omnibus analyses than the data from other three studies.

\section{Methodological issues}

Although the findings reported in this research have important implications for both the study of consciousness and of hemispheric specialisation, there are several methodological issues that must be addressed. In these experiments, emotional or neutral words were presented to participants. This choice of stimuli may at first appear curious, as most previous studies of the lateralisation of emotional perception utilised emotional faces rather than words. There are two reasons why it was critical to use words rather than faces. First, recent research has suggested that it is questionable whether faces can be unconsciously perceived at all (Vuilleumier, 2001). An emotional face is a very salient stimulus and tends to capture attention faster than most other stimulus types (Vuilleumier, 2001; Vuilleumier \& Schwartz, 
2001). This salience makes it difficult to design a paradigm that will reduce the likelihood of conscious perception but still allow unconscious perception to occur (as opposed to reducing the exposure duration to a point at which no perception occurs). This "conscious-or-nothing" tendency is partially explained by a recent electrophysiological study. Pizzagalli and colleagues (Pizzagalli, Lehmann, Hendrick, Regard, Pascual-Marqui, \& Davidson, 2002) found emotion-dependent activation in the fusiform gyrus and extrastriate cortex during the perception of facial stimuli. Specifically, these neural areas became activated approximately $165 \mathrm{~ms}$ post stimulus onset, which coincides with the early stages of face perception. In contrast to faces, words are relatively easy to present in a fashion that will elicit unconscious perception. An emotional word elicits activation in neural structures related to emotion (Isenberg et al., 1999), but does not attract or capture attention to the same degree as does an emotional face. Critically, words are processed semantically at approximately $400-500 \mathrm{~ms}$ post stimulus onset, well after they are processed perceptually (Rugg, Mark, Walla, Schloerscheidt, Birch, \& Allan, 1998). Thus, it is much easier to create an experimental paradigm for the unconscious perception of words than for the unconscious perception of faces.

A second, and related, reason to use words rather than faces is that the exclusion task, one of the few tasks that measures unconscious perception (cf. Snodgrass, 2002), requires linguistic rather than facial stimuli. Studies in which emotional pictures or faces are presented to participants cannot provide an accurate measure of unconscious perception. This shortcoming is due to the fact that both conscious and unconscious perception leads to the same pattern of results (e.g., a faster reaction time). Therefore, it is impossible to demonstrate that the effects of so-called "unconscious" perception do not result from a combination of conscious and unconscious perception. In contrast, the exclusion task pits conscious and unconscious perception in opposition to each other. Conscious perception will lead to one pattern of data and unconscious perception will lead to the opposite pattern of data (Debner \& Jacoby, 1994; Jacoby, 1991; Reingold \& Merikle, 1988, 1990). To date, no reliable version of the exclusion task has been found for stimuli other than words (Merikle \& Daneman, 1998). Therefore, in order to examine hemispheric asymmetries for the unconscious perception of emotion, words were used as the stimuli.

An obvious concern with the use of words is that linguistic material is processed primarily by the LH (for a general review, see Bryden, 1982, and Springer \& Deutsch, 1998). The results of this paper, although pointing to an $\mathrm{RH}$ advantage for the perception of emotionally negative words, do not challenge this well-documented finding. However, they do suggest that some of the early processing related to the words was done in the RH. Earlier research (Bradshaw, Hicks, \& Rose, 1979; Leiber, 1981) has shown an RH 
superiority for the perception of words presented for very brief exposure durations. These studies imply that when stimuli were presented for a short time (e.g., $17 \mathrm{~ms}$ ) the $\mathrm{RH}$ was superior to the $\mathrm{LH}$ at processing the structural characteristics of the word.

\section{Implications for consciousness studies}

The results found in this paper provide important insight into the relation of conscious and unconscious perception. Although a great deal of research has investigated methodological and behavioural factors related to unconscious perception (e.g., Dixon, 1971, 1981; Merikle \& Daneman, 1998), there is a dearth of research investigating how conscious and unconscious perception are related. The research reported here suggests that the conscious and unconscious perception of emotion have reciprocal relations in some sense; conditions that produce an increase in conscious perception of emotional words also appear to produce a decrease in unconscious perception, possibly by lowering the threshold of conscious perception. To our knowledge, this is the first demonstration of the relation between conscious and unconscious perception.

A further issue that arises is what cognitive mechanisms would lead to particular words being consciously perceived but not others. In this series of studies, the semantic characteristics of the words influenced whether the words were consciously perceived. Specifically, emotional words led to more conscious perception than did neutral words in Experiment 1a (for negative information presented to the $\mathrm{RH}$ ), as well as in Experiment $2 \mathrm{~b}$ (for positive information presented to either hemisphere). These findings support the late-selection model of attention (e.g., Deutsch \& Deutsch, 1963), which states that all stimuli that are encoded by the visual system are structurally analysed. After this analysis, particular stimuli are selected to enter into conscious awareness (Deutsch \& Deutsch, 1963). This theory is in contrast to the early-selection models, which state that stimuli are selected to enter conscious awareness before they are completely analysed (Broadbent, 1958). For emotional words (but not neutral words) to have elicited conscious perception suggests that some semantic characteristics of the emotional words were preattentively detected, thus causing these words to be more attention grabbing than the neutral words.

\section{Implications for the study of the lateralisation of emotion}

Neither the right-hemisphere hypothesis nor the valence hypothesis was entirely supported by the results of the experiments reported in this paper. The right-hemisphere hypothesis would have predicted an $\mathrm{RH}$ advantage for 
reports of conscious perception for both negative and positive words, particularly when the visual input characteristics favoured the RH. The valence hypothesis would have predicted an $\mathrm{RH}$ advantage for the conscious perception of negative words (particularly when the visual input characteristics favoured the $\mathrm{RH}$ ) and an $\mathrm{LH}$ advantage for the conscious perception of positive words (particularly when the visual input characteristics favoured that hemisphere). Instead of supporting either of these hypotheses, the data demonstrated that emotional and visual asymmetries interact, and that this interaction differs depending on the emotional valence of the presented words.

These findings suggest that although there is a consistent RH superiority for the conscious perception of negative words, this advantage can only emerge if the visual input characteristics also favour that hemisphere. Therefore, the perception of negative emotion is quite sensitive to interference from visual-perception factors (e.g., exposure duration). In contrast to the perception of negative words, the perception of positive words produced no significant hemispheric asymmetries. This null finding occurred both when the RH demonstrated an overall advantage for visual perception (Experiment 2a) and when the LH demonstrated a somewhat smaller advantage for visual perception (Experiment 2b). The obvious question that arises is why the neural structures involved with the perception of negative emotion could make use of the extra visual information provided by perceptual asymmetries whereas the neural structures involved with the perception of positive information could not. There are two reasons why this might be the case. First, from an evolutionary perspective, it is not as critical to be able to quickly perceive positive information as it is to quickly perceive negative information (Dijksterhuis \& Aarts, 2003). Negative emotions almost certainly involve fast-acting networks similar to the amygdalapulvinar-superior-colliculus circuit, outlined by Morris and colleagues (Morris, Öhman, \& Dolan, 1999), in order to allow the perceiver to avoid any potential dangers. In contrast, positive information rarely puts the perceiver in any social or physical danger. Therefore, there are likely to be fewer networks specialised for the fast processing of this information. Second, the neural structures involved with the perception of positive information produce inconsistent patterns of functional asymmetries (Workman, Peters, \& Taylor, 2000). For example, using ERPs, Davidson and colleagues (e.g., Davidson et al., 1990) demonstrated that the left prefrontal cortex becomes activated during the perception of positive facial expressions. In contrast, Maratos and colleagues (Maratos, Allen, \& Rugg, 2000) found that the perception of positive emotions led to bilateral activation of the orbitofrontal cortex. Given these inconsistent patterns of neural activation, it is not entirely surprising that no clear asymmetries for the perception of positive words were found in the current studies. 
What are the implications of these findings for theories of the lateralisation of emotion? The results of the current experiments as well as other recent research suggest that a new theory of the lateralisation of emotion is necessary. Most of the research reviewed in the introduction of this paper supports the notion that negative emotional information is processed more efficiently in the RH; however, as mentioned above, the results for the perception of positive information are inconsistent. A recent paper by Workman and colleagues (2000) has proposed a model in which the perception of positive information shows a weak LH advantage. In contrast, the perception of negative information is strongly lateralised to the RH. Workman and colleagues referred to this theory as the "left-shift hypothesis". The results of the current research are consistent with this theory.

How would the laterality patterns predicted by the left-shift hypothesis be behaviourally instantiated? There are two obvious predictions. First, negative information will be processed more quickly and more accurately by the RH than by the LH. Second, positive information will show weak trends towards preferential processing by the LH. Importantly, the effect sizes will be larger for the $\mathrm{RH}$ advantage for the perception of negative information than for the LH advantage for the perception of positive information. We would add a final hypothesis based on the current research. We predict that hemispheric asymmetries will be more robust if the visuoperceptual asymmetries and the emotional asymmetries are congruent.

Manuscript received 31 August 2005

Manuscript accepted 13 December 2005

First published online 11 April 2006

\section{REFERENCES}

Atchley, R. A., Ilardi, S. S., \& Enloe, A. (2003). Hemispheric asymmetry in the processing of emotional content in word meanings: The effect of current and past depression. Brain and Language, 84, 105-119.

Beck, A. T., \& Steer, R. A. (1993). Manual for the revised Beck Depression Inventory. San Antonio, TX: Psychological Corporation.

Borod, J. C., Cicero, B. A., Obler, L. K., Welkowitz, J., Erhan, H. M., Santschi, C., et al. (1998). Right hemisphere emotional perception: Evidence across multiple channels. Neuropsychology, $12,446-458$.

Bradshaw, G. J., Hicks, R. E., \& Rose, B. (1979). Lexical discrimination and letter-string identification in the two visual fields. Brain \& Language, 8, 10-18.

Broadbent, D. E. (1958). Perception and communication. London: Pergamon Press.

Bruder, G. E. (1995). Cerebral laterality and psychopathology: Perceptual and event-related potential asymmetries in affective and schizophrenic disorders. In R. J. Davidson \& K. Hugdahl (Eds.), Brain asymmetry (pp. 661-691). Cambridge, MA: MIT Press.

Bryden, M. P. (1982). Laterality: Functional asymmetry in the intact brain. New York: Academic Press. 
Bryden, M. P., Mondor, T. A., Loken, M., Ingleton, M. A., \& Bergstrom, K. (1990). Locus of information in words and the right visual field effect. Brain and Cognition, 14, 44-58.

Canli, T., Desmond, J. E., Zhao, Z., \& Gabrieli, J. D. E. (2002). Sex differences in the neural basis of emotional memories. Proceedings of the National Academy of Science, USA, 99, 1078910794.

Canli, T., Desmond, J. E., Zhao, Z., Glover, G., \& Gabrieli, J. D. E. (1998). Hemispheric asymmetry for emotional stimuli detected with fMRI. NeuroReport, 9, 3233-3239.

Canli, T., Zhao, Z., Desmond, J. E., Glover, G., \& Gabrieli, J. D. E. (1999). fMRI identifies a network of structures correlated with retention of positive and negative emotional memory. Psychobiology, 27, 441-452.

Cicero, B. A., Borod, J. C., Santschi, C., Erhan, H. M., Obler, L. K., Agosti, R. M., et al. (1999). Emotional versus non-emotional lexical perception in patients with right and left brain damage. Neuropsychiatry, Neuropsychology, and Behavioral Neurology, 12, 255-264.

Davidson, R. J. (1995). Cerebral asymmetries, emotion, and affective style. In R. J. Davidson \& K. Hugdahl (Eds.), Brain asymmetry (pp. 361-387). Cambridge, MA: MIT Press.

Davidson, R. J., Ekman, P., Saron, C. D., Senulis, J. A., \& Friesen, W. V. (1990). Approach/ withdrawal and cerebral asymmetry: Emotional expression and brain physiology: I. Journal of Personality and Social Psychology, 58, 330-341.

Davidson, R. J., \& Irwin, W. (1999). The functional neuroanatomy of emotion and affective style. Trends in Cognitive Sciences, 3, 11-21.

Debner, J. A., \& Jacoby, L. L. (1994). Unconscious perception: Attention, awareness, and control. Journal of Experimental Psychology: Learning, Memory, and Cognition, 20, 304-317.

Deutsch, J. A., \& Deutsch, D. (1963). Attention: Some theoretical considerations. Psychological Review, 70, 80-90.

Dijksterhuis, A., \& Aarts, H. (2003). On wildebeests and humans: The preferential detection of negative stimuli. Psychological Science, 14, 14-18.

Dixon, N. F. (1971). Subliminal perception: The nature of a controversy. New York: McGraw-Hill.

Dixon, N. F. (1981). Preconscious processing. Toronto, Canada: Wiley.

Elias, L. J., Bryden, M. P., \& Bulman-Fleming, M. B. (1998). Footedness is a better predictor than is handedness of emotional lateralisation. Neuropsychologia, 36, 37-43.

Isenberg, N., Silbersweig, D., Engelien, A., Emmerich, S., Malavade, K., Beattie, B., et al. (1999). Linguistic threat activates the human amygdala. Proceedings of National Academy of Science USA, 96, 10456-10459.

Jacoby, L. L. (1991). A process dissociation framework: Separating automatic and intentional uses of memory. Journal of Memory and Language, 30, 513-541.

Kuçera, H., \& Francis, W. N. (1982). Frequency analysis of English usage. Boston, MA: Houghton \& Mifflin.

Leiber, L. (1981). Lexical decisions in the right and left cerebral hemispheres. Brain and Language, $3,443-450$.

Maratos, E. J., Allen, K., \& Rugg, M. D. (2000). Recognition memory for emotionally negative and neutral words: An ERP study. Neuropsychologia, 38, 1452-1465.

Merikle, P. M., \& Daneman, M. (1998). Psychological investigations of unconscious perception. Journal of Consciousness Studies, 5, 5-18.

Merikle, P. M., \& Joordens, S. (1997). Parellels between perception without attention and perception without awareness. Consciousness \& Cognition, 6, 219-236.

Merikle, P. M., Joordens, S., \& Stolz, J. A. (1995). Measuring the relative magnitude of unconscious influences. Consciousness \& Cognition, 4, 422-439.

Merikle, P. M., \& Smith, S. D. (2005). Memory for information perceived without awareness. In N. Ohta, R. Uttl, \& C. MacLeod (Eds.), Proceedings of the 5th Tsukuba International Conference on Memory: Dynamic Cognitive Processes. Tokyo: Springer. 
Morris, J. S., Öhman, A., \& Dolan, R. J. (1999). A subcortical pathway to the right amygdala mediating "unseen" fear. Proceedings of the National Academy of Sciences, USA, 96, 16801685.

Nicholls, M.E. R. (1994). Hemispheric asymmetries for temporal resolution: A signal detection analysis of threshold and bias. Quarterly Journal of Experimental Psychology, 47A, 291-310.

Nicholls, M. E. R. (1996). Temporal processing asymmetries between the cerebral hemispheres: Evidence and implications. Laterality, 1, 97-137.

Oscar-Berman, M., Goodglass, H., \& Cherlow, D. G. (1973). Perceptual laterality and iconic recognition of visual materials by Korsakoff patients and normal adults. Journal of Comparative and Physiological Psychology, 82, 316-321.

Pizzagalli, D. A., Lehmann, D., Hendrick, A. M., Regard, M., Pascual-Marqui, R. D., \& Davidson, R. J. (2002). Affective judgments of faces modulate early activity ( $\sim 160 \mathrm{~ms}$ ) within the fusiform gyri. NeuroImage, 16, 663-677.

Psychology Software Tools, Inc. (2001). E-Prime, Version 1.1. Pittsburgh, PA.

Reingold, E. M., \& Merikle, P. M. (1988). Using direct and indirect measures to study perception without awareness. Perception \& Psychophysics, 44, 563-575.

Reingold, E. M., \& Merikle, P. M. (1990). On the inter-relatedness of theory and measurement in the study of unconscious processes. Mind \& Language, 5, 9-28.

Rizzolatti, G., \& Buchtel, H. A. (1977). Hemispheric superiority in reaction time to faces: A sex difference. Cortex, 13, 300-305.

Rugg, M. D., Mark, R. E., Walla, P., Schloerscheidt, A. M., Birch, C. S., \& Allan, K. (1998). Dissociation of the neural correlates of implicit and explicit memory. Nature, 392, 595-598.

Sergent, J. (1982). Methodological and theoretical consequences of variations in exposure duration in visual laterality studies. Perception \& Psychophysics, 31, 451-461.

Sergent, J. (1983). The role of the input in visual hemispheric asymmetries. Psychological Bulletin, 93, $481-512$.

Smith, S. D., \& Bulman-Fleming, M. B. (2001). Unconscious perception and the cerebral hemispheres. Poster presented at the 11th Annual meeting of the Canadian Society for Brain, Behavioural, and Cognitive Science, Québec City, QC, Canada, June 24-26.

Smith, S. D., \& Bulman-Fleming, M. B. (2004). A hemispheric asymmetry for the unconscious perception of emotion. Brain and Cognition, 55, 452-457.

Smith, S. D., \& Merikle, P. M. (2000). Assessing the duration of memory for information perceived without awareness. Consciousness and Cognition, 9 (Pt. 2 of 2), S65-S66.

Snodgrass, M. (2002). Disambiguating conscious and unconscious influences: Do exclusion paradigms demonstrate unconscious perception? American Journal of Psychology, 115, 545579.

Springer, S. P., \& Deutsch, G. (1998). Left brain, right brain (5th ed.). New York: W. H. Freeman \& Company.

Vuilleumier, P. (2001). Emotional facial expressions capture attention. Neurology, 56, 153-58.

Vuilleumier, P., \& Schwartz, S. (2001). Beware and be aware: Capture of spatial attention by fearrelated stimuli in neglect. NeuroReport, 12, 1119-1122.

Watson, D., Clark, L. A., \& Tellegen, A. (1988). Development and validation of brief measures of positive and negative affect: The PANAS scales. Journal of Personality and Social Psychology, 54, 1063-1070.

Workman, L., Peters, S., \& Taylor, S. (2000). Lateralisation of perceptual processing of pro- and anti-social emotions displayed in chimeric faces. Laterality, 5, 237-249. 


\section{APPENDIX 1}

\section{Negative words (target/baseline) used in Experiments 1a and $1 \mathrm{~b}$}

$\begin{array}{llll}\text { gloom/asylum } & \text { death/loser } & \text { attack/filthy } & \text { plague/robber } \\ \text { skull/toxic } & \text { widow/bruise } & \text { boring/hijack } & \text { spider/vulgar } \\ \text { angry/bossy } & \text { break/devil } & \text { horror/rabies } & \text { stress/anxiety } \\ \text { guilt/slimy } & \text { swear/wrath } & \text { danger/nerves } & \text { violent/thunder } \\ \text { crime/waste } & \text { choke/germs } & \text { punish/sicken } & \text { divorce/illness } \\ \text { cruel/idiot } & \text { snake/vomit } & \text { stupid/arsenic } & \text { selfish/revenge } \\ \text { tears/afraid } & \text { tense/ambush } & \text { terror/assault } & \text { anthrax/failure } \\ \text { blame/bully } & \text { blood/cough } & \text { misery/reject } & \text { monster/nervous } \\ \text { panic/slump } & \text { curse/knife } & \text { fright/poison } & \text { torture/sadness } \\ \text { grief/silly } & \text { slave/virus } & \text { burned/injury } & \text { pollute/ominous } \\ \text { growl/satan } & \text { crash/ghost } & \text { scream/suffer } & \text { warning/torment } \\ \text { shock/taxes } & \text { steal/witch } & \text { corpse/lonely } & \text { trouble/suspect } \\ \text { whips/avoid } & \text { chase/fight } & \text { threat/despair } & \text { disease/garbage } \\ \text { grave/noisy } & \text { shame/smite } & \text { prison/savage } & \text { damage/murder } \\ \text { accuse/dagger } & \text { arrest/demons } & \text { cancer/kidnap } & \text { defeat/error }\end{array}$

\section{APPENDIX 2}

\section{Positive words (target/baseline) used in Experiments 2a and $2 b$}

$\begin{array}{llll}\text { adore/foods } & \text { money/pride } & \text { comedy/famous } & \text { attract/worthy } \\ \text { alive/candy } & \text { party/drink } & \text { create/genius } & \text { delight/careful } \\ \text { award/eager } & \text { peace/puppy } & \text { daring/gentle } & \text { flatter/courage } \\ \text { bliss/enjoy } & \text { prize/relax } & \text { desire/giggle } & \text { fortune/diamond } \\ \text { brave/excel } & \text { proud/smile } & \text { friend/gladly } & \text { holiday/ecstasy } \\ \text { charm/extra } & \text { raise/sunny } & \text { heaven/honest } & \text { improve/empathy } \\ \text { cheer/funny } & \text { score/tasty } & \text { invite/joyful } & \text { inspire/helping } \\ \text { clean/gifts } & \text { share/value } & \text { leader/kindly } & \text { miracle/popular } \\ \text { flirt/jewel } & \text { sleek/young } & \text { mature/kitten } & \text { passion/quality } \\ \text { fresh/jokes } & \text { smart/amuse } & \text { mother/lively } & \text { perfect/refined } \\ \text { glory/jolly } & \text { sweet/cared } & \text { please/pretty } & \text { playful/sincere } \\ \text { great/laugh } & \text { treat/trust } & \text { polite/safety } & \text { quality/snuggle } \\ \text { guide/loved } & \text { caring/cuddle } & \text { tender/strong } & \text { respect/succeed } \\ \text { humor/loyal } & \text { beauty/exotic } & \text { thrill/unique } & \text { special/vibrant } \\ \text { marry/lucky } & \text { bright/family } & \text { winner/wisdom } & \text { wealthy/victory }\end{array}$




\section{APPENDIX 3}

\section{Neutral words (target/baseline) used in all experiments}

$\begin{array}{llll}\text { apply/glove } & \text { peach/bench } & \text { bottle/errand } & \text { verbal/cement } \\ \text { label/ethic } & \text { solid/veils } & \text { native/waiter } & \text { closet/beside } \\ \text { touch/piano } & \text { forty/pluck } & \text { mailed/wallet } & \text { barrel/herbal } \\ \text { lunch/roads } & \text { links/abbey } & \text { bishop/turtle } & \text { pardon/float } \\ \text { pages/dwarf } & \text { react/fence } & \text { offers/jacket } & \text { potato/radish } \\ \text { river/guard } & \text { salad/lemon } & \text { lounge/magnet } & \text { vacancy/riddles } \\ \text { clump/penny } & \text { drove/yearn } & \text { income/napkin } & \text { cottage/neutral } \\ \text { align/ridge } & \text { quart/cadet } & \text { talent/rocket } & \text { cabbage/essence } \\ \text { frame/lambs } & \text { quiet/couch } & \text { finger/hopped } & \text { fatigue/jumping } \\ \text { quest/bagel } & \text { brick/rider } & \text { lather/orange } & \text { anatomy/plumber } \\ \text { route/jelly } & \text { cards/years } & \text { castle/salmon } & \text { landing/gliders } \\ \text { swing/lobby } & \text { drain/weigh } & \text { museum/govern } & \text { gallery/tilting } \\ \text { marks/sight } & \text { spark/silky } & \text { patrol/enzyme } & \text { eastern/balloon } \\ \text { drift/boost } & \text { export/arches } & \text { banana/cereal } & \text { surface/plugged } \\ \text { motor/apron } & \text { active/herald } & \text { outfit/hermit } & \text { sticker/lacquer }\end{array}$

